\title{
Second-line chemotherapy for the treatment of metastatic pancreatic cancer after first-line gemcitabine-based chemotherapy: a network meta-analysis
}

\author{
Chiara Citterio ${ }^{1}$, Michela Baccini ${ }^{2}$, Elena Orlandi ${ }^{1}$, Camilla Di Nunzio ${ }^{1}$ and Luigi \\ Cavanna ${ }^{1}$ \\ ${ }^{1}$ Onco-Haematology Department, Hospital Guglielmo da Saliceto, 29121 Piacenza, Italy \\ ${ }^{2}$ Department of Statistics, Informatics, Applications "G. Parenti", Università di Firenze, 50134 Florence, Italy \\ Correspondence to: Luigi Cavanna, email: I.cavanna@ausl.pc.it \\ Keywords: pancreatic cancer; second-line chemotherapy; oxaliplatin; irinotecan; gemcitabine based chemotherapy \\ Received: April 24, $2018 \quad$ Accepted: June 04, $2018 \quad$ Published: July 03, 2018 \\ Copyright: Citterio et al. This is an open-access article distributed under the terms of the Creative Commons Attribution License \\ 3.0 (CC BY 3.0), which permits unrestricted use, distribution, and reproduction in any medium, provided the original author and \\ source are credited.
}

\section{ABSTRACT}

Guidelines for treatment of metastatic pancreatic cancer recommend a second line based on Fluoropyrimidine (FP) alone or in combination with Oxaliplatin (OXA) or Irinotecan (IRI) after a first line treatment based on Gemcitabine (GEM). We conducted a Bayesian network meta-analysis to compare currently available therapies to treat metastatic pancreatic cancer in the second line, considering as efficacy measures overall survival (OS) and progression free survival (PFS). Published randomized trials were identified using electronic databases (MEDLINE, PubMed, https://clinicaltrials.gov/ and American Society of clinical oncology). 8 studies met the inclusion criteria for a total of 1,587 patients and 7 different therapeutic schemes. The results suggested that the use of IRI-FP-Folinic Acid scheme in the second-line treatment of metastatic pancreatic cancer may offer a benefit in terms of OS and PFS for patients not previously treated with these drugs.

\section{INTRODUCTION}

Pancreatic cancer still has a poor prognosis, and progress in the treatment of this disease is poor. Several studies have been conducted regarding the first-line therapy [1], however the second-line remains a field to be explored. Standard first-line therapies are combinations of Gemcitabine (GEM) based chemotherapy, such as GEM plus Nab-paclitaxel or, for the best performing patients, the FOLFIRINOX regimen containing 5-fluorouracil (5FU), Oxaliplatin (OXA), Irinotecan (IRI) and folinic acid (FA). The choice between these two regimens poses a challenging problem: for patients candidate to receive a second-line chemotherapy, the selection depends in part on their previous treatment. Recently, new drugs, such as nanoliposomial IRI in combination with 5-FU and folinic acid (FA), have been approved by the Food and Drug Administration (FDA), especially after disease progression on first-line gemcitabine-based therapy. After a progression from the first line containing GEM, the ASCO
(American Society of Clinical Oncology) guidelines recommend a second line based on Fluoropyrimidine (FP) alone or in combination with OXA or IRI [2]. Currently there are no randomized trials conducted on a large number of patients indicating which of the proposed therapies are the best from the point of view of efficacy. The aim of this project was to compare, through a Bayesian network meta-analysis of published randomized clinical trials, the currently available therapies to treat metastatic pancreatic cancer in the second line, after a first line treatment based on GEM/GEM combination. We focused on both Overall Survival (OS), and Progression Free Survival (PFS).

\section{RESULTS}

The 8 studies included in the network involved a total of 1,587 patients (average age 63.7 years, 56.8\% males) at the second line therapy after a first line of therapy with gemcitabine or gemcitabine combinations. Only for 3 studies $(52.74 \%$ of the 1,587 patients) information was 
available about the exact first line therapy used: 498 patients were treated with gemcitabine monotherapy and 339 with gemcitabine combinations. The patients performance status was reported in 6 studies ( $84 \%$ of the 1,587 patients): patients have a performance status between 0 (502 patients), 1 (741 patients) and 2 (55 patients) (Supplementary Table 1). The second line chemotherapy drugs studied in various combinations were IRI, FP, folinic acid (FA) and OXA. A total of 7 treatments were compared: IRI + FP + FA (1), FP + FA (2), IRI (3), OXA + FP + FA (4), FP (5), IRI + FP (6), FP + OXA (7) (Figure 1).

We had direct information on six comparisons (Figure 1): the comparison between therapeutic scheme 1 $(\mathrm{IRI}+\mathrm{FP}+\mathrm{FA})$ and 2 (FP + FA), between 2 and 3 (IRI), between 2 and 4 (OXA + FP + FA), 2 and 5 (FP), 5 and 6 $(\mathrm{IRI}+\mathrm{FP})$ and 5 and $7(\mathrm{OXA}+\mathrm{FP})$.

For comparisons 2-4, 5-2 and 5-6, data from two studies were available (an individual fixed effects metaanalyzes was performed; since the comparison involved only two studies, it was not reported), while data from only one study were available for the others comparisons.

\section{Results from the network meta-analysis}

In Table 1 the estimates of the pairwise comparisons arising from the network meta-analyses are reported, separately for OS and PFS. The combination IRI-FPFA had better performance than all the other treatments, especially in respect of FP and OXA-FP, both in terms of OS and PFS. Differences among treatments were more evident when focusing on PFS. Results for IRIFP changed according to the outcome: when comparing IRI-FP with OXA-FP-FA, IRI-FP was better in terms of OS while OXA-FP-FA was better in terms of PFS; when comparing IRI-FP with IRI, IRI-FP was better in term of OS while IRI was better in terms of PFS. The median of the $\mathrm{I}^{2}$ distribution was around $85 \%$ for OS $(90 \% \mathrm{Crl}$ :
$34,2 \%-97,9 \%)$ and close to $55 \%$ for PFS (90\% Crl: $0.99 \%-97.7 \%$ ). The combination IRI-FP-FA resulted as having the largest probability of being the best and the lower posterior average rank, in particular when the focus was on PFS (Table 2). FP was the worst treatment in terms of best and average rank in both analyses. These results are confirmed by the analysis of the cumulative probabilities of the treatment rank (Figure 2). When considering OS the most effective therapeutic combinations (SUCRA = $75 \%$ ) were treatment schemes containing Irinotecan: IRI-FP-FA, followed by IRI-FP (58\%), and IRI The SUCRA for the remaining treatments was similar, with values varying between $47 \%$ and $50 \%$. As far as PFS is concerned (Figure 3), the best treatment was IRI-FP-FA $(90 \%)$, followed by OXA-FP-FA plus IRI, both having similar performance in terms of SUCRA $(70 \%$ and, $69 \%$, respectively). Also in this setting, the worst results were observed for the combinations OXA-FP and FP (11\% and $20 \%$ respectively).

\section{DISCUSSION}

The aim of this study was to combine in a networkmeta-analysis published results comparing OS and PFS in patients with metastatic pancreatic cancer treated with different second line therapeutic schemes. The analysis included also schemes that did not contain OXA or IRI, commonly used in clinical practice, especially in Asia [12].

The results suggest that the use of IRI-FP-FA may offer a benefit in terms of both OS and PFS for patients not previously treated with these drugs.

A recent systematic review [13], collected 24 among observational, retrospective, prospective, randomized, comparative and non-comparative studies, comparing FPbased chemotherapy with either OXA or IRI. The conclusion of this study highlight the lack of significant differences in terms of OS and PFS when using a second line therapy based

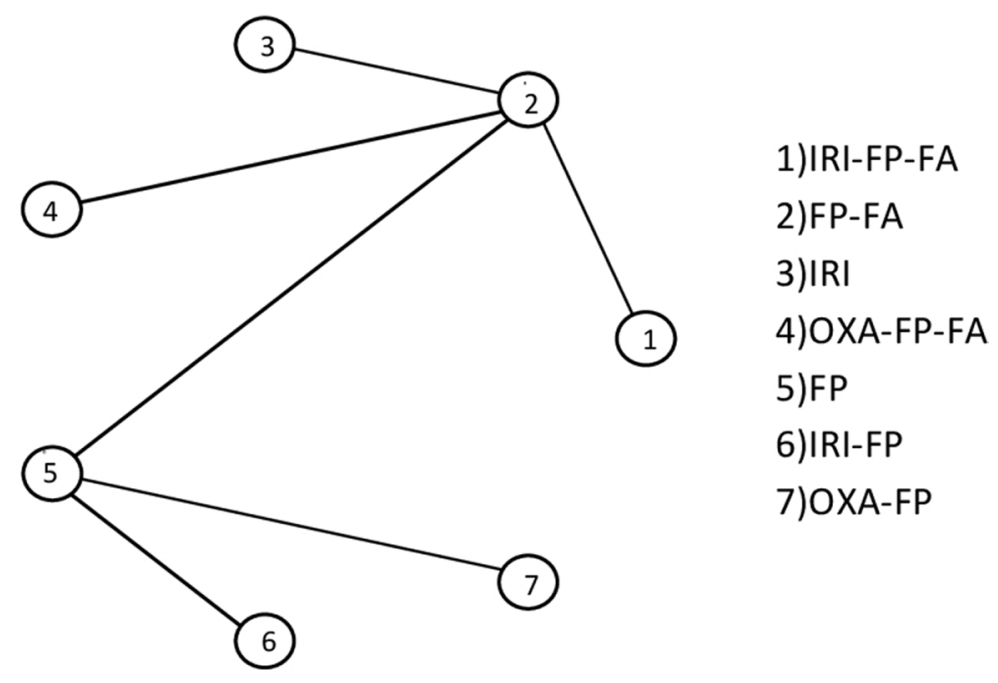

Figure 1: Study network. 
Table 1: Estimated HR (posterior mean, $\mathbf{9 0 \%}$ Credibility Interval) for all pairwise comparisons from the network meta-analysis on OS and PFS

\begin{tabular}{|c|c|c|}
\hline Regimen & Mean & $90 \% \mathrm{CI}$ \\
\hline \multicolumn{3}{|l|}{$\mathrm{OS}$} \\
\hline IRI-FP-FA/FP-FA & 0.67 & $0.22-2.14$ \\
\hline IRI-FP-FA/IRI & 0.68 & $0.14-3.49$ \\
\hline IRI-FP-FA/OXA-FP-FA & 0.65 & $0.15-2.61$ \\
\hline IRI-FP-FA/FP & 0.55 & $0.13-2.34$ \\
\hline IRI-FP-FA/IRI-FP & 0.74 & $0.14-3.78$ \\
\hline IRI-FP-FA/OXA-FP & 0.57 & $0.09-3.53$ \\
\hline FP-FA/IRI & 1.01 & $0.33-3.19$ \\
\hline FP-FA/OXA-FP-FA & 0.96 & $0.41-2.12$ \\
\hline FP-FA/FP & 0.83 & $0.35-1.93$ \\
\hline FP-FA/IRI-FP & 1.09 & $0.34-3.56$ \\
\hline FP-FA/OXA-FP & 0.84 & $0.20-3.49$ \\
\hline IRI/OXA-FP-FA & 0.95 & $0.22-3.78$ \\
\hline IRI/FP & 0.81 & $0.19-3.39$ \\
\hline IRI/IRI-FP & 1.08 & $0.21-5.64$ \\
\hline IRI/OXA-FP & 0.84 & $0.13-5.16$ \\
\hline OXA-FP-FA/FP & 0.85 & $0.20-2.89$ \\
\hline OXA-FP-FA/IRI-FP & 1.14 & $0.28-5.00$ \\
\hline OXA-FP-FA/OXA-FP & 0.88 & $0.18-4.66$ \\
\hline FP/IRI-FP & 1.34 & $0.59-3.03$ \\
\hline FP/OXA-FP & 1.03 & $0.33-3.22$ \\
\hline IRI-FP/OXA-FP & 0.77 & $0.19-3.13$ \\
\hline \multicolumn{3}{|l|}{ PFS } \\
\hline IRI-FP-FA/FP-FA & 0.56 & $0.29-1.06$ \\
\hline IRI-FP-FA/IRI & 0.69 & $0.28-1.70$ \\
\hline IRI-FP-FA/OXA-FP-FA & 0.70 & $0.31-1.52$ \\
\hline IRI-FP-FA/FP & 0.37 & $0.17-0.87$ \\
\hline IRI-FP-FA/IRI-FP & 0.48 & $0.19-1.27$ \\
\hline IRI-FP-FA/OXA-FP & 0.31 & $0.11-0.90$ \\
\hline FP-FA/IRI & 1.23 & $0.66-2.32$ \\
\hline FP-FA/OXA-FP-FA & 1.25 & $0.76-1.97$ \\
\hline FP-FA/FP & 0.66 & $0.40-1.14$ \\
\hline FP-FA/IRI-FP & 0.86 & $0.44-1.77$ \\
\hline FP-FA/OXA-FP & 0.55 & $0.25-1.30$ \\
\hline IRI/OXA-FP-FA & 1.01 & $0.45-2.18$ \\
\hline IRI/FP & 0.53 & $0.24-1.23$ \\
\hline IRI/IRI-FP & 0.70 & $0.28-1.82$ \\
\hline IRI/OXA-FP & 0.45 & $0.17-1.28$ \\
\hline OXA-FP-FA.FP & 0.53 & $0.27-1.11$ \\
\hline OXA-FP-FA/IRI-FP & 0.69 & $0.31-1.67$ \\
\hline OXA-FP-FA/OXA-FP & 0.44 & $0.18-1.20$ \\
\hline FP/IRI-FP & 1.30 & $0.81-2.10$ \\
\hline FP/OXA-FP & 0.84 & $0.44-1.58$ \\
\hline IRI-FP/OXA-FP & 0.65 & $0.30-1.43$ \\
\hline
\end{tabular}


Table 2: Posterior probability of being the best treatment and average rank for the 7 compared treatments, from the network meta-analysis on OS and PFS

\begin{tabular}{lcccc}
\hline Regimen & Mean & Median & Best.perc & $\mathbf{9 0 \%}$ CI \\
\hline OS & & & & \\
IRI-FP-FA & 2.53 & 2 & $1-7$ & 45.64 \\
FP-FA & 4.05 & 4 & $2-6$ & 1.72 \\
IRI & 4.01 & 4 & $1-7$ & 14.43 \\
OXA-FP-FA & 4.14 & 4 & $1-7$ & 8.73 \\
FP & 5.06 & 5 & $2-7$ & 1.02 \\
IRI-FP & 3.53 & 3 & $1-7$ & 17.87 \\
OXA-FP & 4.68 & 5 & $1-7$ & 10.58 \\
PFS & & & & \\
IRI-FP-FA & 1.56 & 1 & $1-4$ & 72.24 \\
FP-FA & 4.05 & 4 & $3-6$ & 0.3 \\
IRI & 2.92 & 3 & $1-6$ & 9.25 \\
OXA-FP-FA & 2.81 & 3 & $1-6$ & 0.16 \\
FP & 5.84 & 6 & $4-7$ & 3.69 \\
IRI-FP & 4.47 & 5 & $2-7$ & 1.49 \\
OXA-FP & 6.35 & 7 & $3-7$ & \\
\hline
\end{tabular}

on IRI or OXA. Our meta-analysis. which included only randomized trials and focused on a larger set of therapies (FP-based chemotherapy with either OXA, IRI and FP-based therapies alone), found a difference.

Sonbol et al. [14] performed a meta-analysis on second-line treatments in patients with pancreatic ductal adenocarcinoma, with the aim of investigating the effectiveness of adding OXA or various IRI formulations to FP after first-line treatment progression. They found that the combination of FP with IRI formulations was the appropriate next line of treatment upon progression after gemcitabine-based chemotherapy regimens, confirming the overall results of our current meta-analysis.

Despite the recent advances in the general overview of cancer therapy, the prognosis of advanced pancreatic cancer still remains poor. For more than 15 years, gemcitabine monotherapy has been the cornerstone of first-line treatment; a new formulation of paclitaxel (nab-paclitaxel) was recently used in combination with gemcitabine as a first-line regimen, with a greater PFS (5.5 versus 3.7 months) [17]. Many recent analyses have examined the use of second-line therapies after this regime: in the global phase III trial MPACT patient receiving second-line therapy after nab-Paclitaxel/GEM experienced a longer median OS than those who did not (12.8 versus 6.3 months, respectively) [18]. The longest total OS values were observed in patients who received first-line nab-Paclitaxel/ GEM followed by fluoropyrimidine-containing second-line regimens (median, 13.5 months); the small number who received second-line FOLFIRINOX reached a median total OS of 15.7 months [18]. Another retrospective analysis led to similar findings, with a median OS of 13.5 months in patients who received second-line treatment after first-line nab-P/Gem (with a benefit with the FOLFIRINOX regimen, 13,8 months of total OS, versus 13,2 with FOLFIRI and 12,8 with FOLFOX/XELOX regimen) [19, 20].

It must be emphasized that most of the studies included in our network have been conducted in China and Japan. This is an important point to bear in mind when interpreting the results, since in the literature there is evidence of heterogeneity between Western and Eastern countries in cancer treatment and in patient's response $[15,16]$.

Our analysis indicates the presence of a certain heterogeneity between studies, in particular for the OS results, and mainly due to the comparison FP-FA and OXA-FP-FA. However, given the small number of studies available for each comparison, it is difficult to make hypothesis about the origin of this heterogeneity. It must be underlined that in this review patients' quality of life and toxicities of the treatment schemes were not considered and that are available only limitated informations about best treatment sequence because only for 3 studies the information about first line therapy are available.

The main limitation of our analysis is the small number of studies that we included in our network, which reflects the fact that in the literature there are only few papers reporting results from clinical trials comparing second-line therapies for pancreatic cancer. Therefore, in order to obtain a complete answer to our research question, further randomized studies are needed.

A better understanding of how an effective first line treatment may influence clinical benefit in subsequent 
treatments is essential. Furthermore, additional indication for second line treatment will depend on enhanced identification of biologic predictors of second line therapy benefit, development of more active regimens, and investigation of the specific toxicity of each regimen.

However, our analysis recommends FP, FA and IRI formulation for the second line treatment after first line GEM/GEM combination, based on OS and PFS evaluation; since there are no data regarding the best second line after FOLFIRINOX first line therapy, further exploration is warranted.

\section{MATERIALS AND METHODS}

\section{Study identification}

Articles, published between 2009 and 2017, were sought in: MEDLINE, PubMed, https://clinicaltrials.gov/ and American Society of clinical oncology (ASCO). The search was based on the following keywords: "pancreatic cancer", "second line" and "chemotherapy". Initially, the online search led to 399 results from PubMed-MEDLINE, 34 from https://clinicaltrials.gov/ and 113 from ASCO.

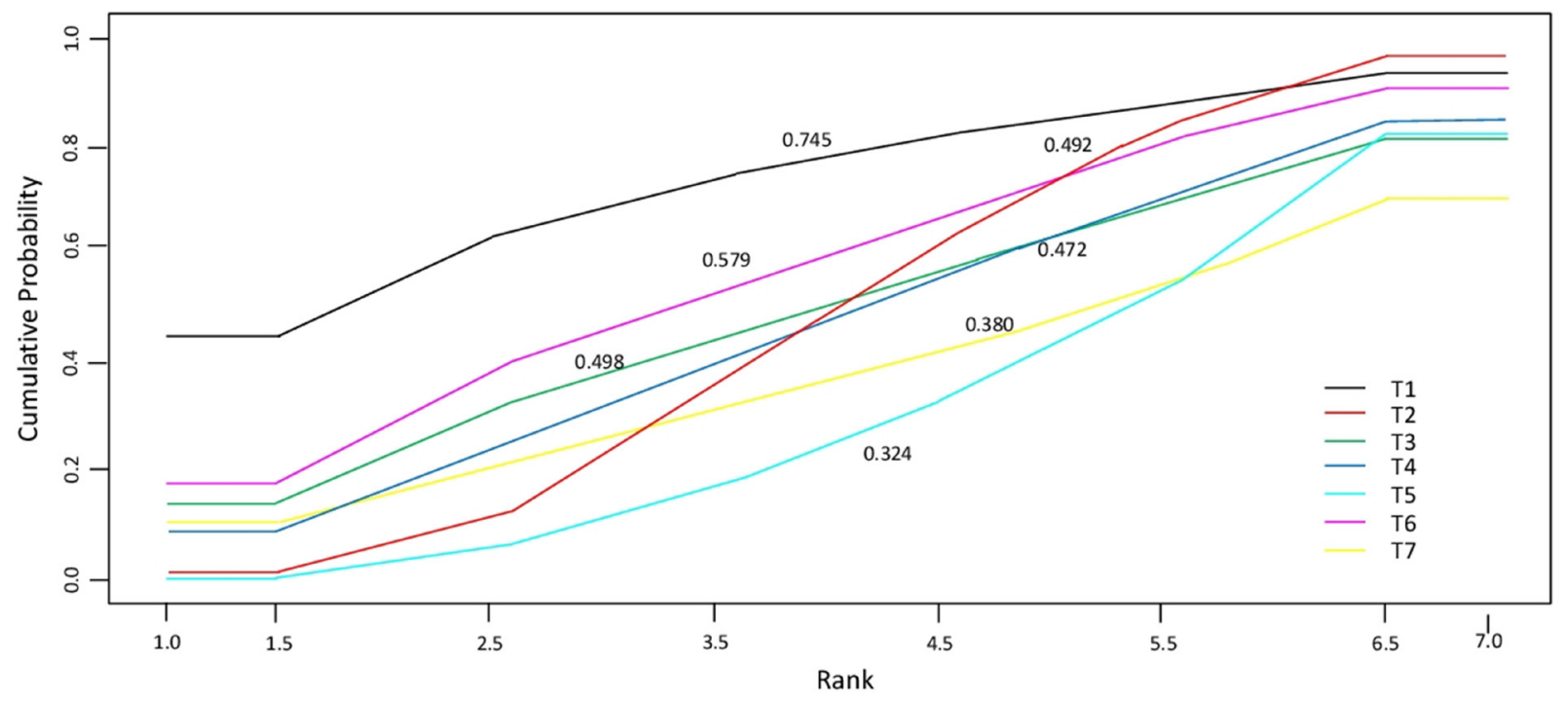

Figure 2: Cumulative probability of the treatment rank and SUCRA for the 7 treatments from the network metaanalysis on OS.

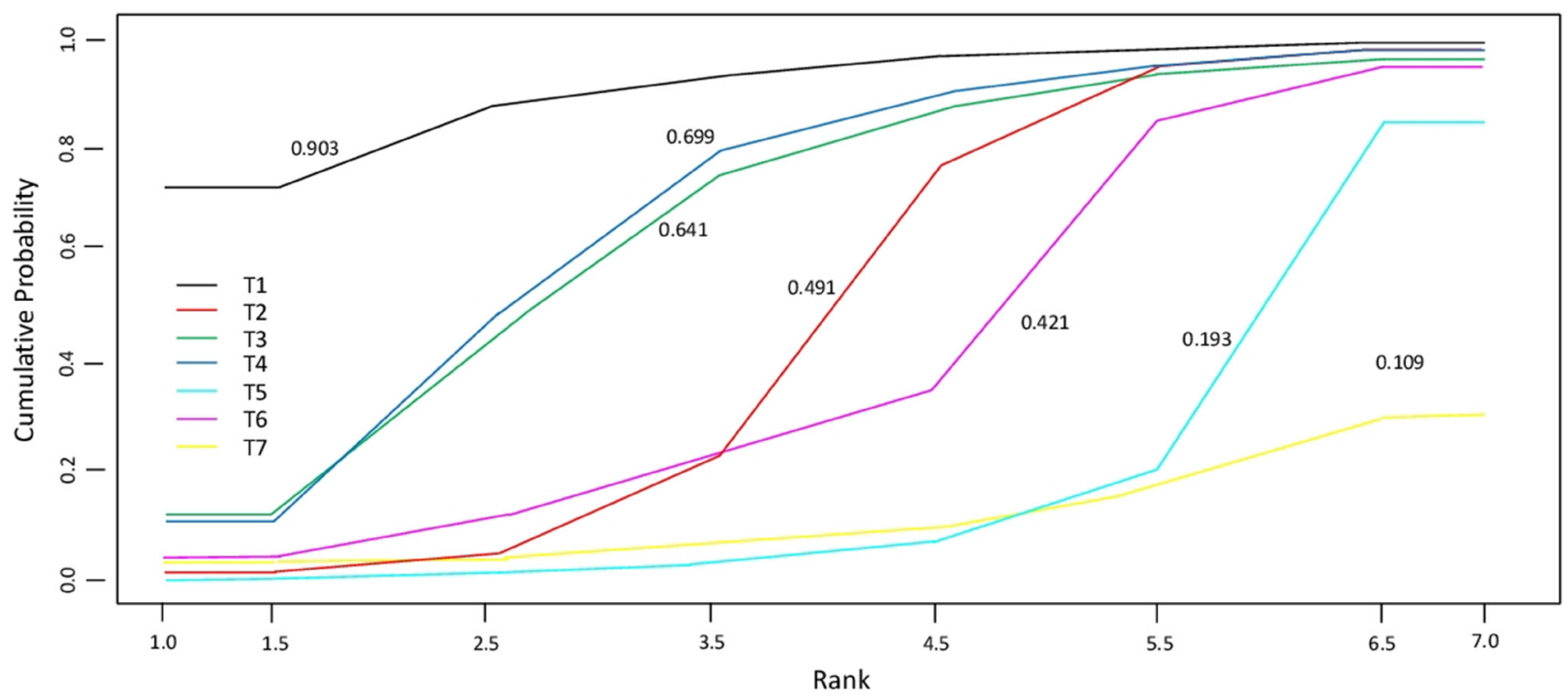

Figure 3: Cumulative probability of the treatment rank and SUCRA for the 7 treatments from the network metaanalysis on PFS. 
After removing duplicates, studies on different treatment lines, different types of cancer, first line not GEM/GEM combination based, not pharmacological therapies and other experimental therapy, a total of 11 studies were considered eligible for further review (Figure 4). Two individual reviewers (E.O. and L.C.) read the articles and extracted from them relevant information, including patient characteristics, study design, sample size, outcome measures and other study characteristics. Of the 11 selected studies 3 were excluded: one was an observational study [3], one did not provide the values of the Hazard Ratio (HR) [4], for a third study, some data were unknown since only the abstract was available [5]. The remaining 8 studies were randomized, phase 2-3 studies; all reported the number of patients and only 5 their average age. Four studies were conducted in Japan, 1 in China, 1 in Canada, 1 in Germany and 1 involved multiple countries (Supplementary Table 1).

\section{Statistical analysis}

Separate analyses were performed for OS and PFS. We focused on the Hazard Ratio (HR). First, for descriptive purposes, single meta-analyses were performed for each comparison with at least two studies available (not reported). Then, a Bayesian meta-analysis network was conducted. The network meta-analysis allows for simultaneous comparisons between multiple treatments, ranking them according to their effectiveness. Moreover, it permits inference also on comparisons never directly observed in ad hoc clinical trials [6-8]. We adopted a Bayesian approach as it provides more reliable estimates of the variability occurring in the network (heterogeneity and inconsistency) and allows to obtain in a more natural way a ranking of the compared treatments. The analyzed outcomes were Overall Survival (OS), and Progression Free Survival (PFS) (Table 3). In the present study, a model was specified that assumed consistency between direct and indirect evidence, because in the network there were no observed comparisons that could be combined to make indirect inference on a third observed comparison (no closed loops in Figure 1) [6-9] The model accounted for possible heterogeneity among the results conducted on the same comparison. Heterogeneity was measured using the $\mathrm{I}^{2}$ statistic [10]. From the network meta-analysis, we obtained a posterior estimate of the HR for each pairwise comparison, with the corresponding 90\% Credibility Interval. For each treatment the cumulative probability

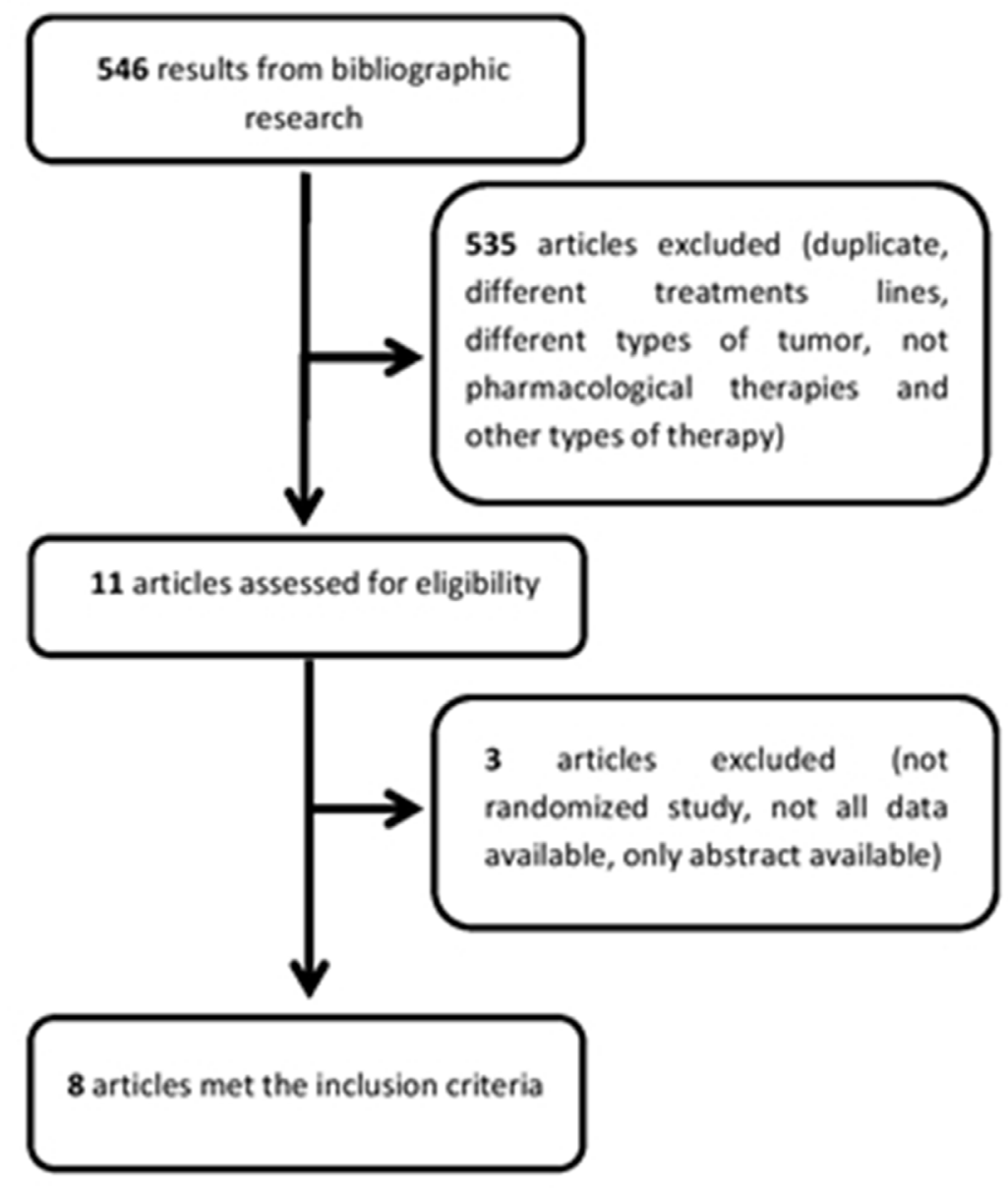

Figure 4: Flow chart illustrating the result of the online search and articles selection. 
Table 3: OS, PFS and HR for the 8 studies included in the network meta-analysis

\begin{tabular}{|c|c|c|c|c|c|c|c|c|c|c|c|}
\hline Author & Treatment & OS $[95 \% \mathrm{CI}]$ & HR & CI $(95 \%)$ & se & $p$ & PFS [95\% CI] & HR & CI $(95 \%)$ & se & $p$ \\
\hline $\begin{array}{l}\text { Gillam et al. [21] } \\
\text { (2016) }\end{array}$ & $\begin{array}{l}\text { IRI-FP-FA } \\
\text { FP-FA (ref.) }\end{array}$ & $\begin{array}{l}6.1[4.8-8.9] \\
4.2[3.3-5.3]\end{array}$ & 0.67 & $0.49-0.92$ & 0.16 & 0.01 & $\begin{array}{l}3.1[2.7-4.2] \\
1.5[1.4-1.8]\end{array}$ & 0.56 & $0.41-0.75$ & 0.15 & 0.00 \\
\hline $\begin{array}{l}\text { Gillam et al. [21] } \\
(2016)\end{array}$ & $\begin{array}{l}\text { IRI } \\
\text { FP-FA (ref.) }\end{array}$ & $\begin{array}{l}4.9[4.2-5.6] \\
4.2[3.6-4.9]\end{array}$ & 0.99 & $0.77-1.28$ & 0.13 & 0.94 & $\begin{array}{c}2.7[2.1-2.9] \\
1.6[1.4-1.8]\end{array}$ & 0.81 & $0.63-1.04$ & 0.13 & 0.10 \\
\hline $\begin{array}{l}\text { Oettle et al. [22] } \\
(2014)\end{array}$ & $\begin{array}{l}\text { FP-FA (ref.) } \\
\text { OXA-FP-FA }\end{array}$ & $\begin{array}{l}3.3[2.7-4.0] \\
5.9[4.1-7.4]\end{array}$ & 0.66 & $0.48-0.91$ & 0.16 & 0.01 & $\begin{array}{l}2.0[1.6-2.3] \\
2.9[2.4-3.2]\end{array}$ & 0.68 & $0.50-0.94$ & 0.17 & 0.02 \\
\hline $\begin{array}{l}\text { Gill et al. [23] } \\
\text { (2016) }\end{array}$ & $\begin{array}{l}\text { FP-FA (ref.) } \\
\text { OXA-FP-FA }\end{array}$ & $\begin{array}{c}9.9[6.7-16.9] \\
6.1[3.2-7.1]\end{array}$ & 1.78 & $1.08-2.93$ & 0.25 & 0.02 & $\begin{array}{l}2.9[1.7-5.1] \\
3.1[1.9-7.2]\end{array}$ & 1.00 & $0.66-1.53$ & 0.22 & 0.99 \\
\hline $\begin{array}{l}\text { Ge et al. [24] } \\
(2014)\end{array}$ & $\begin{array}{l}\text { FP (ref.) } \\
\text { FP-FA }\end{array}$ & $\begin{array}{l}5.5 \\
6.3\end{array}$ & 0.83 & $0.66-1.67$ & 0.36 & 0.08 & $\begin{array}{l}1.9 \\
3.0\end{array}$ & 0.86 & $0.66-1.63$ & 0.33 & 0.86 \\
\hline $\begin{array}{l}\text { Ueno et al. [25] } \\
\text { (2016) }\end{array}$ & $\begin{array}{l}\text { FP (ref.) } \\
\text { FP-FA }\end{array}$ & $\begin{array}{l}6.1 \\
6.3\end{array}$ & 0.82 & $0.54-1.22$ & 0.20 & 0.46 & $\begin{array}{l}2.7 \\
3.8\end{array}$ & 0.56 & $0.37-0.85$ & 0.21 & 0.00 \\
\hline $\begin{array}{l}\text { Ioka et al. [26] } \\
\text { (2017) }\end{array}$ & $\begin{array}{l}\text { FP (ref.) } \\
\text { FP-IRI }\end{array}$ & $\begin{array}{l}5.8 \\
6.8\end{array}$ & 0.75 & $0.51-1.09$ & 0.19 & 0.13 & $\begin{array}{l}1.9 \\
3.5\end{array}$ & 0.77 & $0.53-1.11$ & 0.19 & 0.02 \\
\hline $\begin{array}{l}\text { Mizuno et al. [27] } \\
\text { (2013) }\end{array}$ & $\begin{array}{l}\text { FP (ref.) } \\
\text { FP-IRI }\end{array}$ & $\begin{array}{l}5.9 \\
6.9\end{array}$ & 0.75 & $0.51-1.09$ & 0.19 & 0.13 & $\begin{array}{l}1.93 \\
3.57\end{array}$ & 0.77 & $0.53-1.11$ & 0.19 & 0.18 \\
\hline $\begin{array}{l}\text { Ohkawa et al. [28] } \\
\text { (2015) }\end{array}$ & $\begin{array}{l}\text { FP } \\
\text { OXA-FP (ref.) }\end{array}$ & $\begin{array}{l}6.9 \\
7.4\end{array}$ & 1.03 & $0.79-1.34$ & 0.13 & 0.82 & $\begin{array}{l}2.8 \\
3.0\end{array}$ & 0.84 & $0.65-1.08$ & 0.13 & 0.18 \\
\hline
\end{tabular}

Abbreviations: $\mathrm{OS}=$ Overall Survival, $\mathrm{HR}=$ Hazard Ratio, $\mathrm{CI}=$ Confidence Interval, $\mathrm{se}=$ standard error, $p=p$-value, $\mathrm{PFS}=$

Progression Free Survival, Ref. $=$ reference treatment.

of the treatment rank was drawn and the area under the defined curve (SUCRA) calculated. The SUCRA, which can also be obtained through a transformation of the average rank, provides a measure of the relative performance of the treatment compared to the others. The greater the value of the SUCRA, i.e. the greater the portion of area under the curve, the better the treatment performance [11]. All statistical analyses were performed using R software (Core Team (2017). R: A language and environment for statistical computing. R Foundation for Statistical Computing, Vienna, Austria. URL https:// www.R-project.org/), and the R2WinBUGS package. Codes have been written ad hoc for this analysis.

\section{Abbreviations}

(5-FU) 5-fluorouracil; (ASCO) American Society of Clinical Oncology; (FP) Fluoropyrimidine; (FA) folinic acid; (FDA) Food and Drug Administration; (GEM) Gemcitabine; (cGEM) gemcitabine combination; (IRI) Irinotecan; (nd) no data; (OS) Overall Survival; (OXA) Oxaliplatin; (PS) Performance Status; (PFS) Progression Free Survival.

\section{Author contributions}

Chiara Citterio: performed the research/study, collected data, analyzed data, wrote the paper; Michela Baccini: planned and supervised the statistical analysis, wrote the paper; Elena Orlandi: revised the selected papers, wrote the paper; Camilla Di Nunzio: wrote the paper; Luigi Cavanna: designed the research/study, revised the selected papers, wrote the paper.

\section{ACKNOWLEDGMENTS}

The work was carried out as the final thesis of a second level master in advanced biostatistics for clinical research, Padua University.

\section{CONFLICTS OF INTEREST}

The authors have no financial support or relationships that may pose conflict of interest.

\section{REFERENCES}

1. Gresham GK, Wells GA, Gill S, Cameron C, Jonker DJ. Chemotherapy regimens for advanced pancreatic cancer: a systematic review and networkmeta-analysis. BMC Cancer. 2014; 14:471.

2. Sohal DP, Mangu PB, Khorana AA, Shah MA, Philip PA, O'Reilly EM, Uronis HE, Ramanathan RK, Crane CH, Engebretson A, Ruggiero JT, Copur MS, Lau M, et al. Metastatic pancreatic cancer: American Society of clinical Oncology clinical practice guideline. J Clin Oncol. 2016; 34:2784-96.

3. Yoo C, Hwang JY, Kim JE, Kim TW, Lee JS, Park DH, Lee SS, Seo DW, Lee SK, Kim MH, Han DJ, Kim SC, 
Lee JL. A randomised phase II study of modified FOLFIRI.3 vs modified FOLFOX as second-line therapy in patients with gemcitabine-refractory advanced pancreatic cancer. British Journal of Cancer. 2009; 101:1658-1663.

4. Cereda S, Reni M, Rognone A, Ghidini M, Belli C, Longoni S, Fugazza C, Brioschi M, Nicoletti R, Balzano G, Passoni P, Villa E. XELIRI or FOLFIRI as salvage therapy in advanced pancreatic cancer. Anticancer Res. 2010; 30:4785-90.

5. Kimura G, Takahashi H, Umemoto K, Watanabe K, Sasaki M, Hashimoto Y, Imaoka H, Ohno I, Mitsunaga S. Efficacy of S-1 compared to modified FOLFIRINOX as second-line chemotherapy regimens after gemcitabine plus nab-paclitaxel for patients with metastatic pancreatic cancer. Journal of Clinical Oncology. 2017; 35:449-449.

6. Lumley T. Network meta-analysis for indirect treatment comparisons. Stat Med. 2002; 21:2313-24.

7. Lu G, Ades A. Assessing evidence inconsistency in mixed treatment comparisons. Journal of the American Statistical Association. 2012; 101:447-459. https://doi.org/10.1198/0 16214505000001302 .

8. Higgins JP, Jackson D, Barrett JK, Lu G, Ades AE, White IR. Consistency and inconsistency in network meta-analysis: concepts and models for multi-arm studies. Res Synth Methods. 2012; 3:98-110.

9. Higgins J, Thompson S, Deeks J, Altman D. Measuring inconsistency in meta-analyses. BMJ. 2003; 327:557-560.

10. Patsopoulos N, Evangelou E, Ioannidis J. Sensitivity of between-study heterogeneity in meta-analysis: proposed metrics and empirical evaluation. Int J Epidemiol. 2008; $37: 1148-57$.

11. Mbuagbaw L, Rochwerg B, Jaeschke R, Heels-Andsell D, Alhazzani W, Thabane L, Guyatt GH. Approaches to interpreting and choosing the best treatments in network meta-analyses. Systematic Reviews. 2017; 6:79.

12. Morizane C, Okusaka T, Furuse J, Ishii H, Ueno H, Ikeda M, Nakachi K, Najima M, Ogura T, Suzuki E. A phase II study of S-1 in gemcitabine-refractory metastatic pancreatic cancer. Cancer Chemother Pharmacol. 2009; 63:313-319.

13. Petrelli F, Inno A, Ghidini A, Rimassa L, Tomasello G, Labianca R, Barni S. Second line with oxaliplatin- or irinotecan-based chemotherapy for gemcitabine-pretreated pancreatic cancer: A systematic review. Eur J Cancer. 2017; 81:174-182.

14. Sonbol MB, Firwana B, Wang Z, Almader-Douglas D, Borad M, Makhoul I, Ramanathan R, Ahn D, BekaiiSaab T. Second-line treatment in patients with pancreatic ductal adenocarcinoma: A meta-analysis. Cancer. 2017; 123:4680-4686.

15. Sasako M, Dakuramoto S, Katai H, Kinoshita T, Furukawa H, Yamaguchi T. Five-year outcomes of a randomized phase III trial comparing adjuvant chemotherapy with S-1 versus surgery alone in stage II-III gastric cancer. J Clin Oncol. 2011; 29:4387-93.

16. Bang YI, Kim YW, Yang HK, Chung HC, Park YK, Lee KH, Lee KW, Kim YH, Noh SI, Cho JY, Mok YJ, Kim YH, Ji J, et al. Adjuvant capecitabine and oxaliplatin for gastric cancer after D2 gastrectomy (CLASSIC): a phase 3 open-label, randomized controlled trial. Lancet. 2012; 379:315-21.

17. Goldstein D, El-Maraghi RH, Hammel P, Heinemann V, Kunzmann V, Sastre J, Scheithauer W, Siena S, Tabernero J, Teixeira L, Tortora G, Van Laethem JL, Young R, et al. Nab-Paclitaxel plus gemcitabine for metastatic pancreatic cancer: long-term survival from a phase III trial. J Natl Cancer Inst. 2015; 107.

18. Chiorean EG, Von Hoff DD, Tabernero J, El-Maraghi R, Ma WW, Reni M, Harris M, Whorf R, Liu H, Li JS, Manax V, Romano A, Lu B, et al. Second-line therapy after nabpaclitaxel plus gemcitabine or after gemcitabine for patients with metastatic pancreatic cancer. Br J Cancer. 2016; 115:188-194.

19. Giordano G, Febbraro A, Milella M, Vaccaro V, Melisi D, Foltran L, Zagonel V, Zaniboni A, Bertocchi P, Bergamo F, Passardi A, Musettini G, Giommoni E, Iop A. Impact of second-line treatment (2L T) in advanced pancreatic cancer (APDAC) patients (pts) receiving first line nab-paclitaxel (nab-P) + gemcitabine $(\mathrm{G})$ : an Italian multicentre real life experience. (Poster presented at: ASCO 2016 Annual Meeting; [abstract 4124]). Journal of Clinical Oncology. 2016; 34:4124-4124.

20. Gourgou-Bourgade S, Bascoul-Mollevi C, Desseigne F, Ychou M, Bouché O, Guimbaud R, Bécouarn Y, Adenis A, Raoul JL, Boige V, Bérille J, Conroy T. Impact of FOLFIRINOX compared with gemcitabine on quality of life in patients with metastatic pancreatic cancer: results from the PRODIGE 4/ACCORD 11 randomized trial. J Clin Oncol. 2013; 31:23-29.

21. Wang-Gillam A, Li C, Bodoky G, Dean A, Shan Y, Jameson G, Macarulla T, Lee KH, Cunningham D, Blanc JF, Hubner RA, Chiu C, Schwartsmann G, et al. Nanoliposomal irinotecan with fluorouracil and folinic acid in metastatic pancreatic cancer after previous gemcitabine-based therapy (NAPOLI-1): a global, randomised, open-label, phase 3 trial. Lancet. 2016; 387:545-57.

22. Oettle H, Riess H, Stieler J, Heil G, Schwaner I, Seraphin J, Gorner M, Molle M, Greten TF, Lakner V, Bischoff S, Sinn M, Dörken B, et al. Second-line oxaliplatin, folinic acid, and fluorouracil versus folinic acid and fluorouracil alone for gemcitabine-refractory pancreatic cancer: Outcomes from the CONKO-003 trial. J Clin Oncol. 2014; 32:2423-2429.

23. Gill S, Ko YK, Cripps C, Beaudoin A, Dhesy-Thind S, Zulfiqar M, Zalewski P, Do T, Cano P, Lam WYH, Dowden S, Grassin H, Stewart J, Moore M. PANCREOX: a randomized phase III study of fluorouracil/leucovorin with 
or without oxaliplatin for second-line advanced pancreatic cancer in patients who have received gemcitabine-based chemotherapy. J Clin Oncol. 2016; 34:3914-3920.

24. Ge F, Xu N, Bai Y, Ba Y, Zhang Y, Li F, Xu H, Jia R, Wang $\mathrm{Y}$, Lin L, Xu J. S-1 as monotherapy or in combination with leucovorin as second-line treatment in gemcitabinerefractory advanced pancreatic cancer: A randomized, openlabel, multicenter, phase II study. The Oncologist. 2014; 19:1133-1134.

25. Ueno M, Okusaka T, Omuro Y, Isayama H, Fukutomi A, Ikeda M, Mizuno N, Fukuzawa K, Furukawa M, Iguchi H, Sugimori K, Furuse J, Shimada K, et al. A randomized phase II study of S-1 plus oral leucovorin versus S-1 monotherapy in patients with gemcitabine-refractory advanced pancreatic cancer. Annals of Oncology. 2016; 27:502-508.

26. Ioka T, Komatsu Y, Mizuno N, Tsuji A, Ohkawa S, Tanaka M, Iguchi H, Ishiguro A, Kitano M, Satoh T, Yamaguchi
T, Takeda K, Kida M, et al. Randomised phase II trial of irinotecan plus S-1 in patients with gemcitabine-refractory pancreatic cancer. British Journal of Cancer. 2017; 116:464-471.

27. Mizuno N, Yamao K, Komatsu Y, Munakata M, Ishiguro A, Yamaguchi T, Ohkawa S, Kida M, Ioka T, Takeda K, Kudo T, Kitano M, Iguchi H, et al. Randomized phase II trial of S-1 versus S-1 plus irinotecan (IRIS) in patients with gemcitabine-refractory pancreatic cancer. Journal of Clinical Oncology. 2013; 31:263-263.

28. Ohkawa S, Okusaka T, Isayama H, Fukutomi A, Yamaguchi K, Ikeda M, Funakoshi A, Nagase M, Hamamoto Y, Nakamori S, Tsuchiya Y, Baba H, Ishii H, et al. Randomised phase II trial of S-1 plus oxaliplatin vs S-1 in patients with gemcitabine-refractory pancreatic cancer. $\mathrm{Br} \mathrm{J}$ Cancer. 2015; 112:1428-14. 